\title{
Tomato Crop Mapping Using Object Oriented Classification at Shoolagiri and Surroundings, Krishnagiri District, Tamil Nadu, India
}

\author{
V.A. Archana ${ }^{1 *}$, S. Rama Subramoniam ${ }^{2}$, K. Ganesha Raj ${ }^{3}$ and V. ANandhi ${ }^{4}$ \\ ${ }^{1}$ Agricultural Information Technology, Tamil Nadu \\ Agricultural University, Coimbatore, India \\ ${ }^{2}$ RRSC-South, NRSC/ISRO, Bengaluru, India \\ ${ }^{3}$ RRSC-South, NRSC/ISRO, Bengaluru, India \\ ${ }^{4}$ Tamil Nadu Agricultural University, Coimbatore, India \\ *Corresponding author:
}

\section{A B S T R A C T}

\begin{tabular}{|c|}
\hline Keywords \\
\hline $\begin{array}{l}\text { Object-oriented } \\
\text { classification, } \\
\text { Support Vector } \\
\text { Machine, K-Nearest } \\
\text { Neighbour, Rule- } \\
\text { based classification }\end{array}$ \\
\hline Article Info \\
\hline $\begin{array}{l}\text { Accepted: } \\
22 \text { July } 2019 \\
\text { Available Online: } \\
10 \text { August } 2019\end{array}$ \\
\hline
\end{tabular}

\section{Introduction}

Remote Sensing is the art and science of technology obtaining information about the earth surface without having any physical contact with it. In the field of agriculture, remote sensing has found significant uses. Remote sensing data has the potential and the capacity to provide spatial information; features and phenomena on earth on an almost real-time basis. They have the potential not only in estimating crop yield but also of
The object-oriented image analysis delineates segments of homogeneous image areas. The delineated segments are classified to real world objects based on spectral, textural, neighbourhood an object specific shape parameter. Object-oriented classification of highresolution imagery is a challenging job for the remote sensing community. Identification of the object-oriented classes based on objects leads to better classification. In this project, the object-oriented classification for tomato in Shoolagiri and surrounding villages of Krishnagiri district in Tamil Nadu, India. In rule-based classification, there are six parameters were attempted:i) Normalized Difference Vegetation Index ii) Maximum Difference iii) Mean-Layer3, Layer2, Layer1 iv) Asymmetry v) Shape Index vi) Border Index. Based on the Maximum Difference, it classifies Tomato for rule-based oriented classification techniques. Object-oriented classification techniques were estigated using Support Vector Machine and K-Nearest Neighbour approaches. The accuracy of the classification gained through rule-based classification.

identifying crop classes. Crop classification methods by using satellite images and ground observation use of satellite images in agriculture. In those days uses of these methods were not tradition because satellite images were expensive, and their spatial resolution was low. Many applications of remote sensing in the agricultural sector are crop production forecasting, assessment of crop damage, crop acreage estimation, crop identification, identification of planting and harvesting dates, crop yield modelling and 
estimation, soil mapping, soil moisture estimation, land cover and land degradation mapping, monitoring of droughts, land mapping, etc...

Importance of nutritional values of vegetables and its contribution to achieve nutritional security cannot be overstated. With growth in economy and income of the country, the consumption of vegetables is continuously increasing, thereby raising their demand.

The vision Tamil Nadu 2023 document lays great stress on micro irrigation to exclusive parks for vegetables. Area expansion of vegetable the area is limited to 0.5 ha./Farmer.

Tomato is one of the dominant horticulture crops of our country. Tomato is one of the most important "Protective foods" because of its nutritive value. The tomato crop is grown from almost MSL to an altitude of $1500 \mathrm{~m}$ in tropical and sub-tropical regions, with annual rainfall of $60-150 \mathrm{~cm}$.

Very high rainfall during its growth is harmful. When it has grown under hot weather condition, it is cultivated as an irrigated crop. The winter crop which is planted from August to September. The winter crop is ideal for organic farming of tomato. The best suitable land for cultivating tomato is well drained sandy loam soil with organic content is high, the soil with high acidity is not suitable for cultivating tomato.

With an estimated production of $18,735.91$ thousand metric tonnes in 2013-2014. The second largest producer of tomatoes in the world is India, almost $11 \%$ of the total world produce of tomatoes is cultivated in India. In India, West Bengal is the largest producer of tomatoes. In Tamil Nadu, Krishnagiri is the largest producer of tomatoes. The total global area under tomato is 46.16 lakh ha and the global production is to the tune of 1279.93 lakh tonnes.

Object-oriented image classification is the description of image objects, or segments, with similar texture, colour, and tone (Green and Congalton, 2012). This approach allows for consideration of shape, size, context as well as spectral content. Object-oriented information extraction based on spectrum character, geometry and structure information. This approach clarifies an image that is not only represented by single pixels, but also in meaningful image objects and their bilateral relationships.

The same characteristics among pixels include colour, shape, size and grain. Then it creates objects with same attributes. It provides a whole bunch of original features and techniques for automated image analysis. Thus, we classify the image not through single pixels, but rather through extracted objects. Assessing the state of the earth surface is a vital requirement for global change research (Committee on Global Change Research, National Research Council, 1999; Jung et al., 2006; Lambin et al., 2001).

Classification and mapping vegetation are an important professional task for operating natural resources as vegetation provides a base for all living beings and plays an essential role in affecting global climatology, such as influencing terrestrial $\mathrm{CO}_{2}$ (Xiao et al., 2004). Vegetation mapping also presents important information for understanding the natural and man-made environments through quantifying vegetation cover from local to global scales at a given time point or over a continuous period. It is critical to obtain current states of vegetation cover in order to initiate vegetation protection and restoration programs (Egbert et al., 2002; He et al., 2005). 


\section{Data used and study area}

Tamil Nadu, India Krishnagiri district

Shoolagiri and surrounding Villages

Table.1

\begin{tabular}{|l|l|l|l|}
\hline Sensor & Resolution & $\begin{array}{l}\text { Swath } \\
\text { width }\end{array}$ & $\begin{array}{l}\text { Spectral } \\
\text { Bands }\end{array}$ \\
\hline LISS- & $5.8 \mathrm{~m}$ & $24-70$ & $0.52-$ \\
IV & & & $0.5($ Green $)$ \\
\hline & & & $0.62-$ \\
& & & $0.68($ Red $)$ \\
\hline & & & $0.77-$ \\
& & & $0.86(\mathrm{NIR})$ \\
\hline & & & \\
\hline
\end{tabular}

Materials and Methods

\section{Study area}

The part of Shoolagiri and surrounding villages, Krishnagiri district in Tamil Nadu has been selected as the study area. The area comprises of land cover features like vegetation, open areas, some major roads, built-up, water bodies. The geographical coordinates i.e., latitude and longitude of shoolagiri is $12.6647661^{\circ} \mathrm{N}$ and $78.0127037^{\circ} \mathrm{E}$ respectively. IST (Indian Standard Time) that has been followed in Shoolagiri villages is located in the UTC time zone 5.30. Shoolagiri Chinnar Dam reservoir constructed across the river Ponniyar in 19811984 has a total catchment area of 43.62 sq.km and irrigates several thousand hectares of agricultural land.

The tomato crop is grown from almost MSL to an altitude of $1500 \mathrm{~m}$ in tropical and subtropical regions, with annual rainfall of 60$150 \mathrm{~cm}$. The winter crop is ideal for organic farming of tomato. The best suitable land for cultivating tomato is well drained sandy loam soil with organic content is high. The number of occupied persons of shoolagiri block is 84790 whereas 93110 are non-working. And out of 84790 working person 27823 peoples are fully dependent on cultivation.

\section{Methodology}

\section{Segmentation}

The first step in object-based classification is segmentation, which is the process of segregation the image into a set of discrete, non-overlapping regions (Devereux et al., 2004). Furthermore, land cover of different types as, particularly buildings and vegetation areas which are of interest in this research, presents in different shapes and sizes in the image, and cannot be well separated by single resolution segmentation.

To overcome the under segmentation and over segmentation problems, the multi-resolution segmentation, embedded in eCognition Developer software, was employed in this research. Smaller land cover types such as single or dwarf trees are well segmented in the lower levels of segmentation, while trees or other objects in higher levels of segmentation are more meaningful for larger land cover types.

Three parameters including scale, shape and compactness should be defined for each level of segmentation in multiresolution segmentation. A semi-automatic process of selection of optimal parameters, was used in this study.

\section{Results and Discussion}

The first step in object-based classification is segmentation, which is the process of segregation the image into a set of discrete, non-overlapping regions. Three parameters of multiresolution segmentation scale, shape and compactness tested with different 
combination as scale of 8 to 12 and shape of 0.2 to 0.5 and compactness of 0.2 to 0.6. Initially the LISS-IV was segmented with the scale parameter of 8 , shape of 0.4 and compactness of 0.5 .

\section{Rule-based classification}

\section{NDVI}

NDVI is a measure in remote sensing also used in agriculture capturing how much more near infrared light is reflected compared to visible red. In Rule-Based Classification, the distribution of NDVI values for tomato, forest, other crops, settlement, water has totally different values for vegetation it ranges about 0.25-0.67.

\section{Maximum difference}

The table 5 shows the different values for tomato, forest, other crops, settlement as well as water body taken from the image object information in eCognition software. The distribution of Maximum-Difference for tomato, forest, other crops, settlement, water has different values for tomato it ranges about 1.2-1.7

In Rule-Based Classification, the distribution of NDVI values for tomato, forest, other crops, settlement, water has totally different values for vegetation it ranges about 0.25 0.67. The distribution of MaximumDifference for tomato, forest, other crops, settlement, water has different values for tomato it ranges about 1.2-1.7. The distribution of Mean Layer3(NIR), Layer2(Red), Layer1(Green), Asymmetry, Border Index, Shape Index values has mingled values for Vegetation, Settlement and Water.

\section{Classifier}

\section{K-Nearest Neighbour}

The knearest neighbour algorithm is amongst the best of all machine learning algorithms an object is classified by a most vote of its neighbors, with the object is assigned to the class amongst its $\mathrm{k}$ nearest neighbors. For $\mathrm{KNN}$ classification the operation given as train, configuration classes, the features that given are Maximum Difference, NDVI and again operation was set as apply. The result shows for Tomato the KNN classification acquires the area of 359.026 hectares.

Table.2 Segmentation Parameter

\begin{tabular}{|l|l|l|l|}
\hline Image & Scale & Shape & Compactness \\
\hline LISS-IV & 8 & 0.4 & 0.5 \\
\hline
\end{tabular}

Table.3 Accuracy Assessment

\begin{tabular}{|c|c|c|}
\hline \multicolumn{3}{|c|}{$\begin{array}{l}\text { GT points from LISS-IV data } \\
\text { Accuracy=- }\end{array}$} \\
\hline S.No. & Classifier & Accuracy \\
\hline 1. & Rule-Based Classification & $78 \%$ \\
\hline 2. & Support Vector Machine & $63 \%$ \\
\hline 3. & K-Nearest Neighbour & $65 \%$ \\
\hline
\end{tabular}


Fig.1 Location map of Shoolagiri and surrounding villages, Krishnagiri district
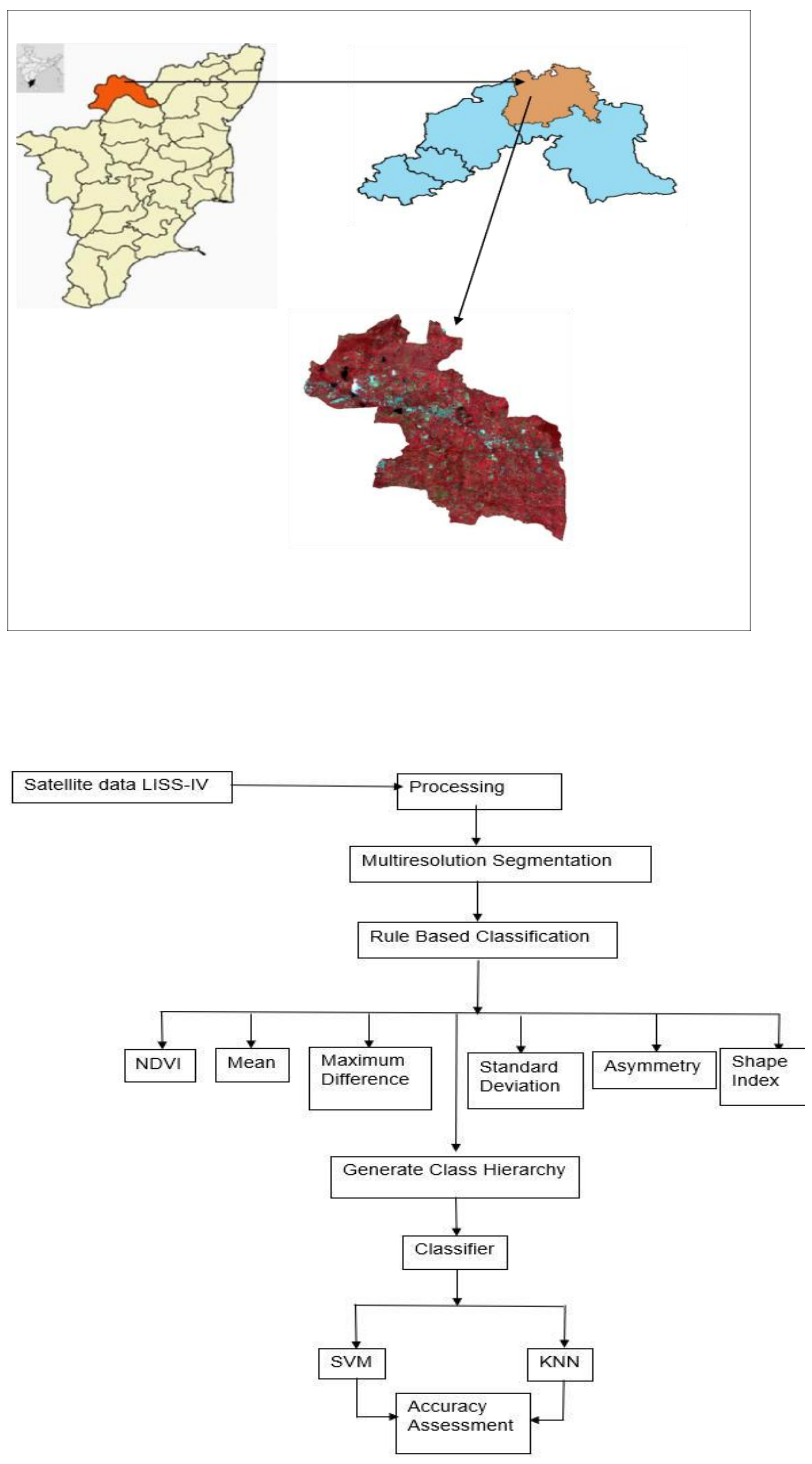

Fig:2 Flowchart - Process of object-oriented classification

Fig.3 Image Segmentation

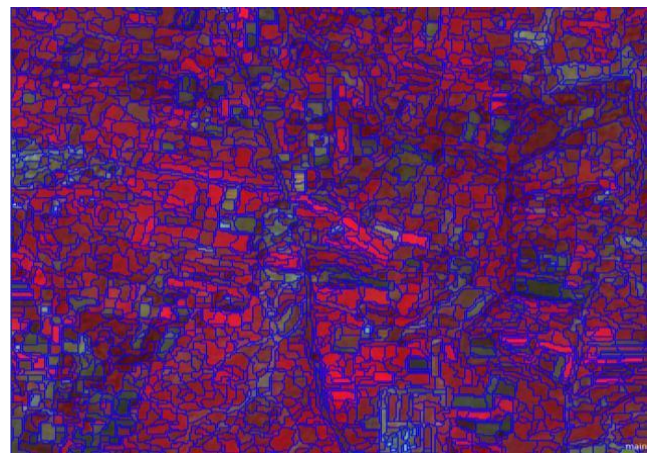


Fig.4 Rule-Based Classification

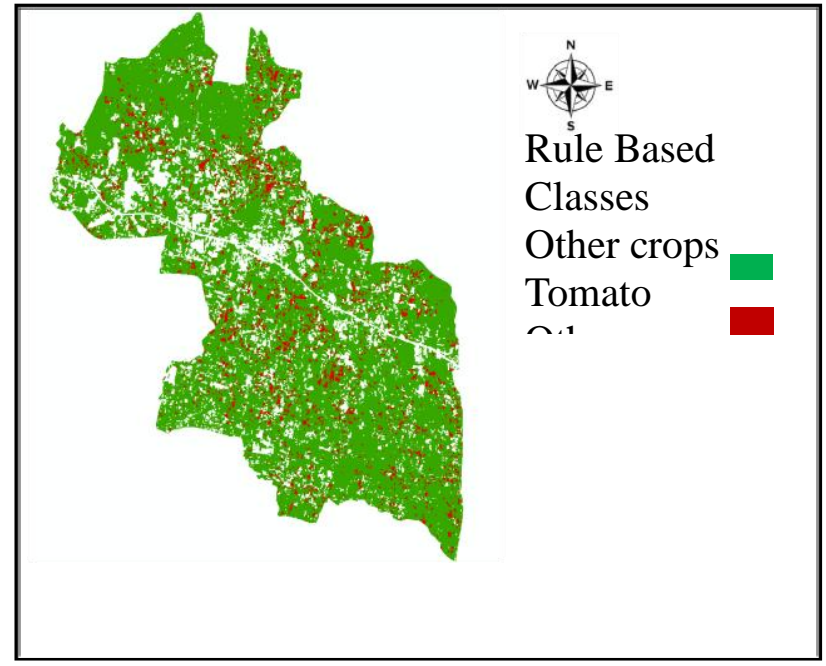

Fig.5 KNN Classifier
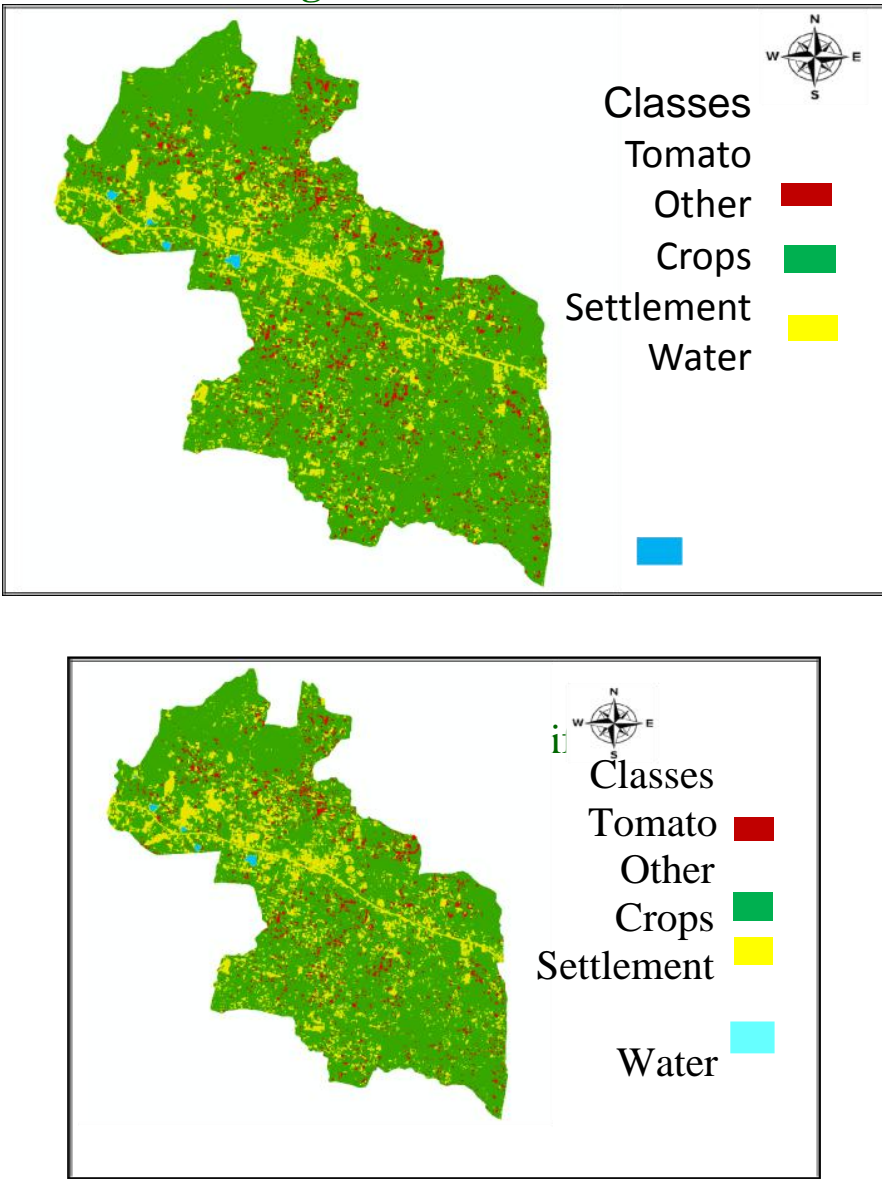

The standard SVM takes a set of input data possible classes the input is a member of and evaluate, for given input, which of two given a set of training examples. For SVM 
classification the operation given as train, configuration classes, the features that given are Maximum Difference, NDVI and again operation was set as apply. The result shows for Tomato the SVM classification acquires the area of 351.309 hectares.

According to area, for Tomato the SVM classification acquires the area of 351.309 hectares and for Tomato the KNN classification acquires the area of 359.026 hectares and for Tomato the Rule-Based Classification acquires the area of 509.749 hectares. The overall comparison the area classified by Rule-Based Classification was better.

\section{Accuracy assessment}

For the accuracy assessment, LISS-IV data was used. Some features were identified and discriminated from the given data. The collected points were used to assess the classification accuracy and further validation.

In conclusion, the study was discussed about the object-oriented classification for LISS-IV data using eCognition software, the objects were clearly segmented in the scale parameter of 8 , shape of 0.4 and compactness of 0.5 the images were properly segmented. The classes are assigned by selected samples through the class hierarchy. After sample selection classes were assigned with different names. The parameters such as NDVI, Maximum Difference, Mean, Asymmetry, Shape Index, Border Index. In NDVI, it gives the feature values is same for all crops like tomato, forest and all other crops, all mingled with the vegetation. Maximum Difference were given as features value for the SVM classification and KNN classification. For the accuracy assessment the area has been calculated and ground truth points were collected from the LISS-IV data. The ground truth and classified output were used for the validation. Rule-
Based Classification wasidentified as the most suitable classification. The classifiers obtain the different level of accuracy were SVM $63 \%$ and other classifiers up to $\mathrm{KNN} 65 \%$ and Rule-Based Classification up to $78 \%$ with ground truth values that was obtained from the LISS-IV data. Hence, Rule-Based Classification was the better classification for the vegetables study.

\section{References}

Al-Bakri JT, Taylor JC. (2003) Application of NOAA AVHRR for monitoring vegetation conditions and biomass in Jordan, J Arid Environ, vol. 54 (pg. 579-93)

Amit Kumar Verma, P.K Garg, K.S Hari Prasad, V.K Dadhwal (2016) Classification of LISS IV Imagery using Decision Tree Methods. The International Archives of the Photogrammetry, Remote Sensing and Spatial Information Sciences, Volume XLI-B8, pg. 1061-1066

Bagan H, Yang Y, Ma J, et al., (2005) Land cover classification from MODIS EVI times-series data using SOM neural network, Int JRemote Sens, Vol. 26 (pg. 4999-5012)

Balazs Dezso Istvan Fekete, David Gera, Roberto Giachetta and IstvanLaszlo (2012). Object-Based Image Analysis in Remote Sensing Applications Using Various Segmentation Techniques Communicated by Andras Benczur; Pp. 103-120

Camilo A. Pulido Rojasa, Leonardo E. Solaque Guzmanb, and Nelson F. Velasco Toledoc A Comparative Analysisof Weed Images Classification Approaches in Vegetables Crops Engineering Journal, 21: 82-98.

Cingolani AM, Renison D, Zak MR, et al., (2004) Mapping vegetation in aheterogeneous mountain rangeland 
using landsat data: an alternative method to defineandclassify land-cover units, RemoteSens Environ, vol. 92, pg. 84-97

E. Frauman, E. Wolff Segmentation ofVery High Spatial Resolution Satellite Images in Urban Areas for SegmentsBased Classification. Institut de Gestion de I'Environnement et d'Amenagement $\mathrm{du}$ Territoire, Universite Libre de Bruxelles, 50 av. F. Roosevelt, CP 130/02, 1050 Brussels

Haitao Li, Haiyan Gu, Yanshun Han and Jinghui Yang (2010): Object-oriented classification of high-resolution remote sensing imagery based on an improved colour structure code and a support vector machine, International Journal of Remote Sensing, 31:6, pg.1453-1470

Md. Rejaur Rahman. S.K. Saha (June2008) Multi-resolution Segmentation for Object-based Classification and Accuracy Assessment of Land Use/Land Cover Classification using Remotely Sensed Data J. Indian Soc. Remote Sens. vol 36, pg. 189-201.

Rosso PH, Ustin SL, Hastings A.
(2005)Mapping marshland vegetation of San FranciscoBay, California, using hyperspectral data, Int J RemoteSens, vol. 26, pg. 5169-91.

Sun Xiaoxiaa Zhang and Jixiana Liu Zhengjuna. (2004) An ObjectOrientedClassification Method on High Resolution Satellite Data. 25th ACRS 2004 ChiangMai, Thailand, pg.347-350

Wenxia WEI, Xiuwan Chen, Ainai Ma Object-Oriented Information

Extraction and Application in Highresolution Remote Sensing Image Institute of Remote Sensing GIS Peking University Beijing, P.R. China Earthquake Engineering Research Center, China Earthquake Administration, Beijing, pg.3803-3806

Wu Chaofan, Deng Jinsong, Wang Ke*, Ma Ligang, Amir Reza Shah Tahmassebi Object-based classification approach for greenhouse mapping using Landsat-8 imagery Institute of Applied Remote Sensing \& Information Technology, Zhejiang University, Hangzhou 310058, China. Vol. 9, pg.78-88

\section{How to cite this article:}

Archana, V.A., S. Rama Subramoniam, K. Ganesha Raj and ANandhi, V. 2019. Tomato Crop Mapping Using Object Oriented Classification at Shoolagiri and Surroundings, Krishnagiri District, Tamil Nadu, India. Int.J.Curr.Microbiol.App.Sci. 8(08): 2472-2479. doi: https://doi.org/10.20546/ijcmas.2019.808.287 